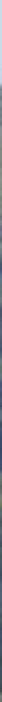
a

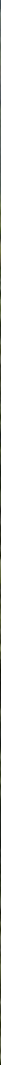

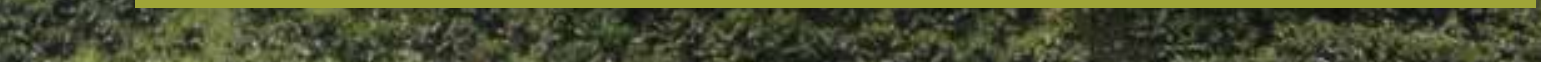

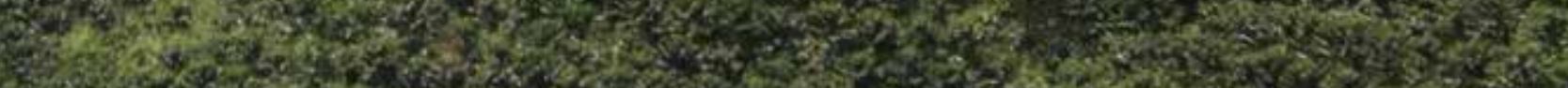

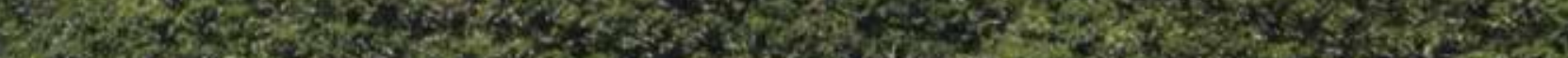

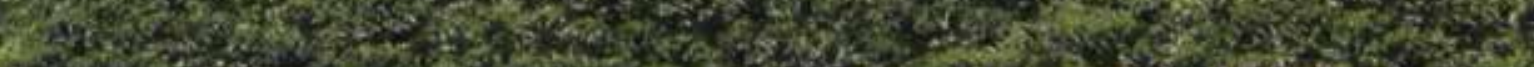




\section{DENSIDADES, EDADES Y RENOVACIÓN}

José Raúl Rendón Sáenz *

La densidad de siembra del cultivo de café es un factor clave en la producción que se debe definir desde la etapa de establecimiento, para optimizar el uso del terreno en el sistema de producción.

\section{DENSIDAD Y RENOVACIÓN DE CAFETALES}

\section{Densidad}

Las variedades de porte bajo cultivadas en Colombia permiten el uso de mayores densidades de siembra comparadas con las densidades utilizadas en variedades de porte alto. Las mayores producciones obtenidas con variedades de porte bajo se han alcanzado con densidades de siembra de 10.000 plantas por hectárea y para variedades de porte alto con densidades de siembra de 5.000 plantas por hectárea.

Establecer altas poblaciones de plantas cuando las condiciones de variedad, suelo, clima y económicas lo favorecen, genera mayor eficiencia en el uso de los recursos.

Arreglo espacial

El arreglo espacial hace referencia a la disposición de las plantas en el terreno de una forma ordenada, para facilitar las labores de manejo agronómico y promover espacio para los cultivos intercalados o asociados.

Para obtener por ejemplo una densidad de 10.000 tallos por hectárea se pueden establecer diversos arreglos espaciales, siembras en cuadro, rectángulo, triángulo, con uno o dos tallos por sitio, así: 

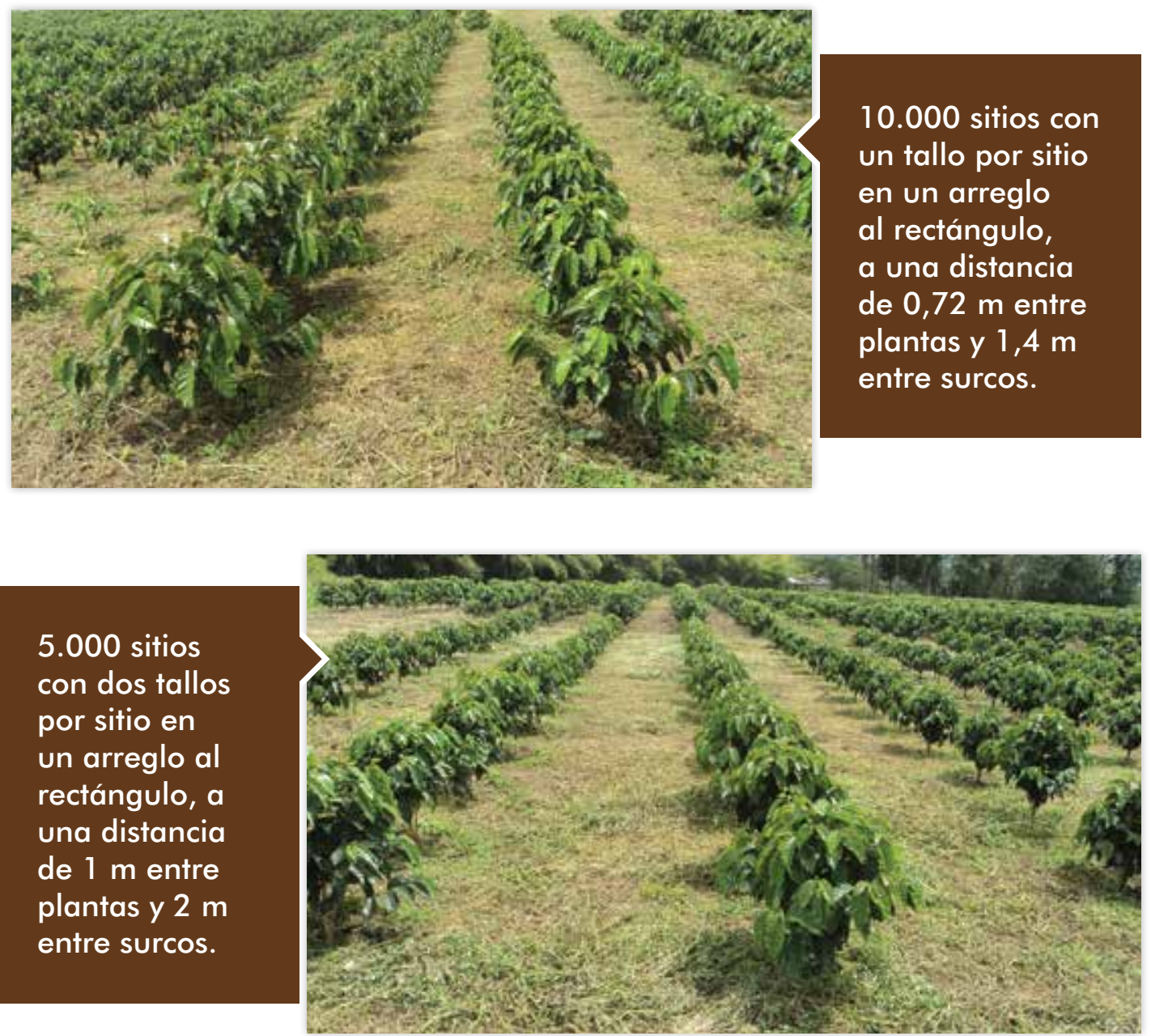

5.000 sitios con dos tallos por sitio en un arreglo al rectángulo, a una distancia de $1 \mathrm{~m}$ entre plantas y 2 m entre surcos.

10.000 sitios con un tallo por sitio en un arreglo al cuadrado, a una distancia de $1 \mathrm{~m}$ entre plantas y $1 \mathrm{~m}$ entre surcos. 


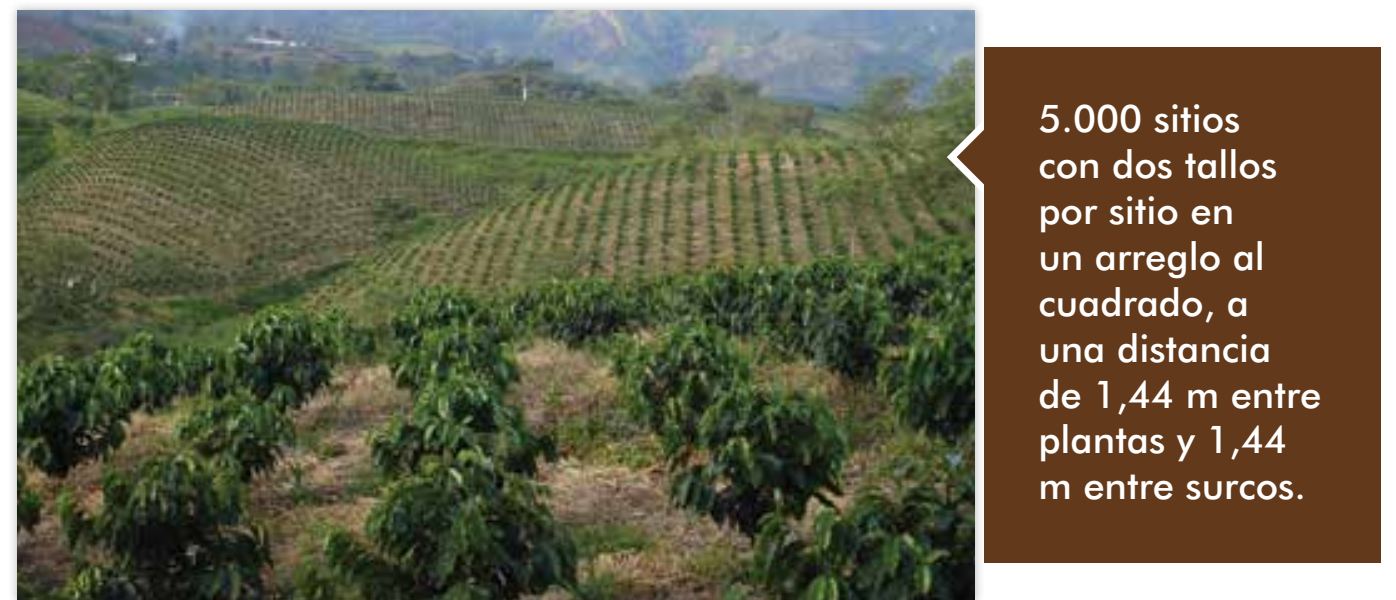

En el caso de utilizar colinos de café descopados con dos tallos por sitio, las distancias de siembra se pueden ampliar, generando una reducción de costos en el establecimiento hasta del $45,2 \%$.

Cultivos asociados o intercalados

La decisión de establecer cultivos asociados como plátano en barreras o cultivos intercalados como fríiol o maíz entre los surcos de café, durante la etapa de establecimiento o en las zocas, se debe determinar bajo criterios de manejo agronómico independiente para cada cultivo.

Maíz intercalado en siembras de café.

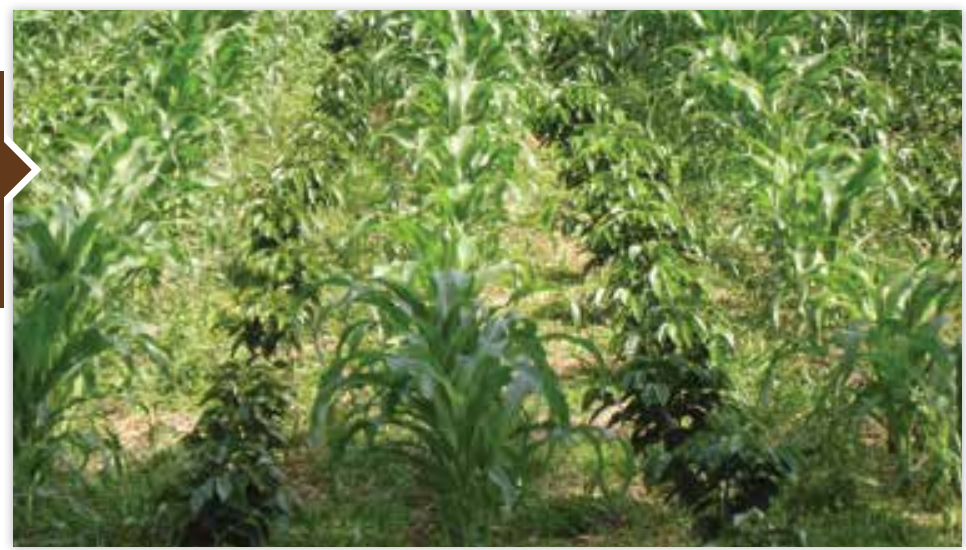




\section{Estructura de edad de los cafetales}

¿Cuándo renovar un cafetal?

La duración del ciclo de producción o número de años que un cafetal puede permanecer sin renovación se determina según el número de cosechas con las que se consigue el máximo promedio de producción anual y depende a la vez de la densidad de siembra. Las características de una plantación envejecida son: excesivo crecimiento en altura de los árboles, baja producción y desplazamiento de la zona productiva del árbol hacia la punta de las ramas y hacia el tercio superior del tallo, pérdida de ramas bajeras y dificultad para realizar las prácticas de manejo del cultivo como son la cosecha y el manejo de plagas y enfermedades.

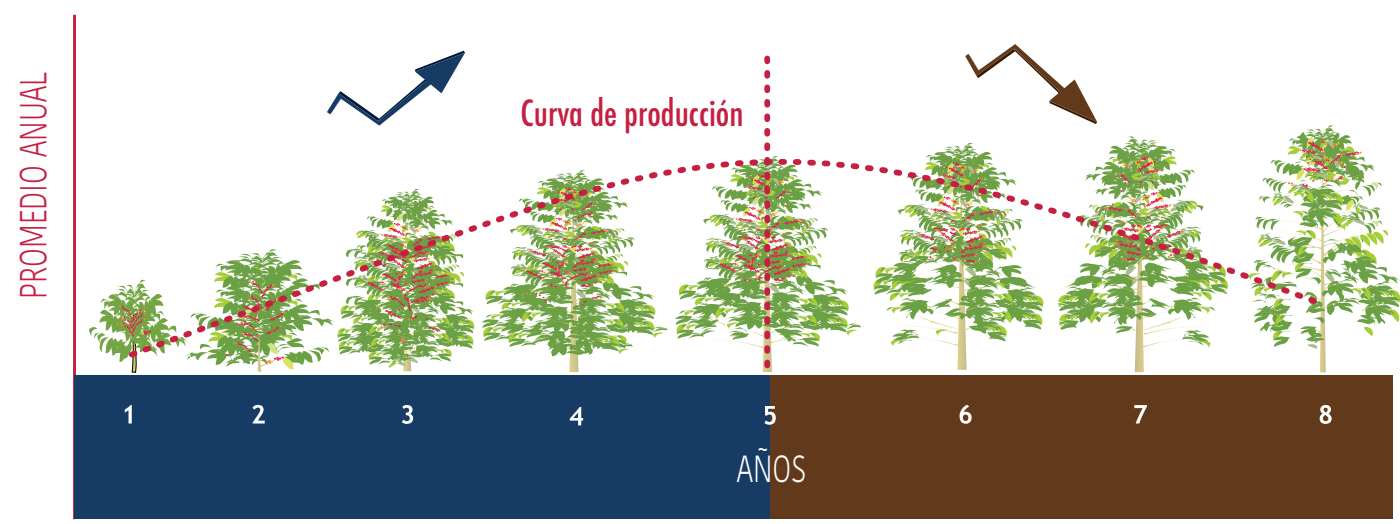

Aumento de la producción

Disminución de la producción

Épocas para renovar por siembras o zocas

Los patrones de comportamiento de la lluvia en las regiones cafeteras, asociados a los patrones de distribución de las cosechas, han permitido generar recomendaciones regionales para definir la época adecuada de siembra.

En general, se recomienda realizar las siembras en la época de lluvia, luego de haber finalizado la cosecha principal de la zona. 
Las renovaciones por zoca y las podas, en regiones con cosecha principal registrada en el primer semestre del año, se deben realizar al inicio del segundo semestre; para regiones con cosecha principal en el segundo semestre, las renovaciones se deben realizar al inicio del primero, y en zonas donde la cosecha se distribuye igualmente en los dos semestres se recomienda la renovación en el semestre con menor intensidad de lluvias.

\section{Alternativas para la renovación de cafetales}

A medida que el cultivo de café envejece y la competencia entre las plantas avanza, se presenta el agotamiento de la capacidad productiva de las plantas y su manejo se hace cada vez más complejo. Dentro de las prácticas de manejo del cultivo, la renovación de los cafetales a partir de diferentes métodos de poda o zoca se consideran labores de menor costo, comparadas con la renovación por siembra.

Elegir el tipo de renovación adecuado para cada caso y momento, depende de un correcto diagnóstico del sistema de producción establecido. Para facilitar la toma de decisiones se presentan algunas consideraciones sobre las alternativas de renovación en cafetales.

\section{Renovación por siembra}

Con la siembra se puede ajustar el número de plantas por hectárea y el arreglo espacial con el fin de alcanzar altas producciones y facilitar el manejo del cultivo. Una buena siembra depende de la calidad del colino, una correcta preparación del terreno, corrección de la acidez del suelo, trazo adecuado, tamaño óptimo de los hoyos y buena humedad del suelo.

\section{Condiciones de uso}

$\rightarrow$ Cuando el objetivo es cambiar de variedad o el número de sitios perdidos en un lote es superior al $30 \%$ se recomienda la renovación por siembra. 
Adecuación del lote $y$ trazado para la renovación por siembra.

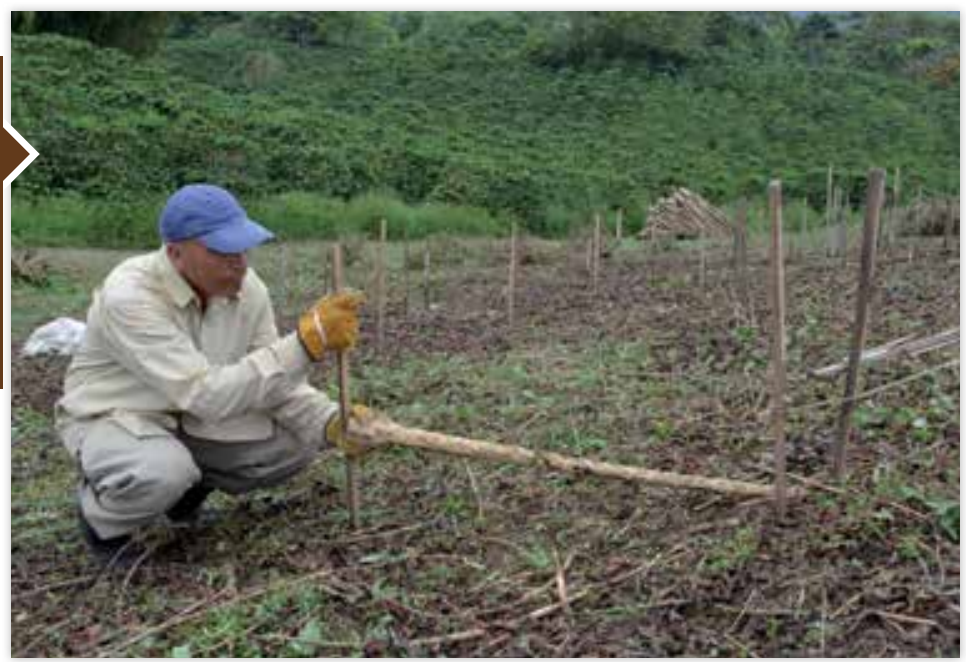

Poda calavera

Consiste en eliminar total o parcialmente las ramas, dejando $10 \mathrm{~cm}$ de longitud, y dejando el tallo con libre crecimiento o con poda por encima de 1,80 m. En esta poda se permite el desarrollo de todos los chupones a lo largo del tallo, con lo cual se estimula la pronta recuperación de nudos productivos en los árboles. 
Los nuevos chupones que se forman en el tallo principal se deben seleccionar para dejar uno o dos chupones por sitio, según la densidad de siembra inicial.

Condiciones de uso

$\rightarrow$ En zonas donde las condiciones de clima y suelo son limitantes para el crecimiento de la planta de café, la poda pulmón permite recuperar la producción en menor tiempo comparada con la zoca común.

$\rightarrow$ La duración del ciclo es de dos cosechas como máximo.

$\rightarrow$ Esta poda no se recomienda cuando los cafetales carecen de ramas en el tercio inferior del árbol.

- Es una alternativa para estabilizar la producción cuando la mayoría de lotes del predio han envejecido y se pretende ordenar el predio con lotes de diferentes edades.

\section{Zoca común}

En la renovación por zoca común el corte del tallo se hace a $30 \mathrm{~cm}$ sobre el suelo; los nuevos chupones que se forman en la porción de tallo se seleccionan y se dejan uno o dos chupones por sitio, según la densidad de siembra inicial.
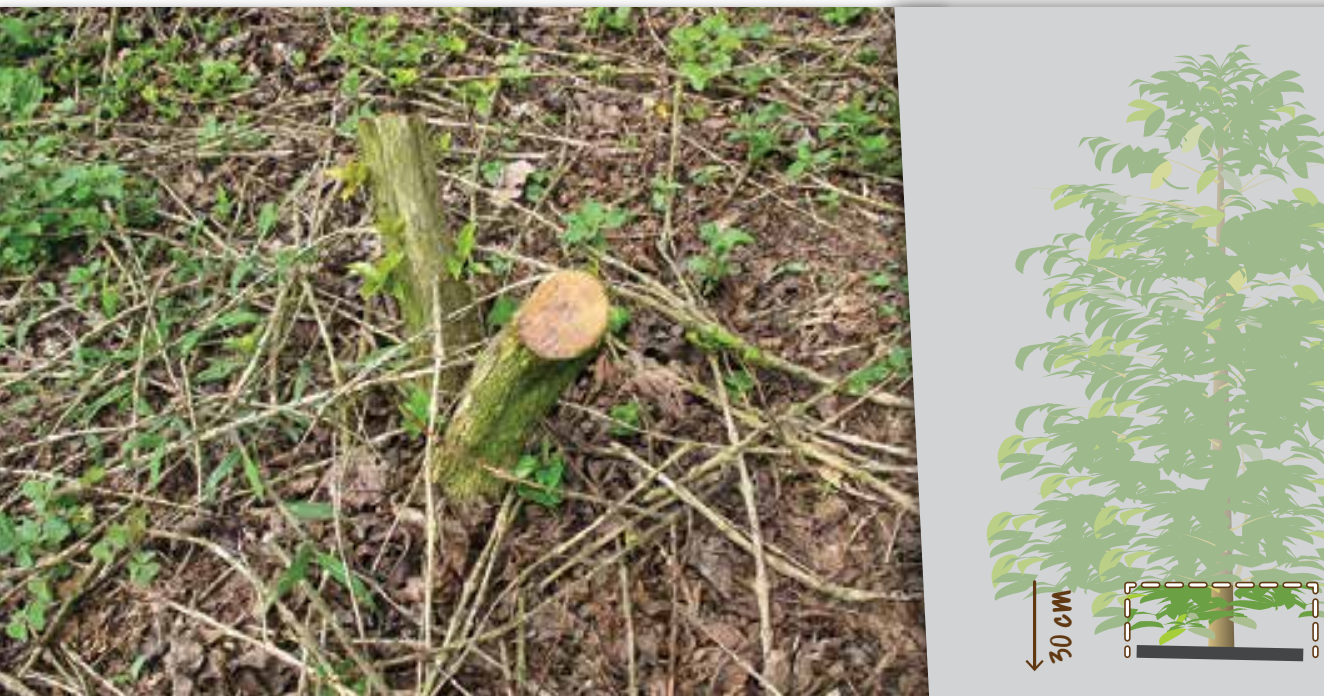
La zoca común facilita incrementar la densidad de tallos cuando se tienen distancias de siembra amplias dejando dos chupones por sitio o intercalando dentro del surco un sitio con uno y otro con dos chupones.

Condiciones de uso

> En zonas donde la planta de café presenta crecimiento acelerado, este sistema garantiza la recuperación de la producción y la duración de ciclos de producción de cuatro a cinco cosechas.

- Esta alternativa permite recuperar los sitios perdidos, a partir de las resiembras, y establecer cultivos intercalados durante el primer año de crecimiento de la plantación.

$\rightarrow$ La zoca común se recomienda como alternativa para mantener estable la duración de los ciclos de producción.

Descope

El descope en cafetales se hace especialmente en variedades de porte alto como la variedad Tabi. Consiste en suspender el crecimiento del tallo principal, cuando las plantas alcanzan una altura entre 1,60 y $1,80 \mathrm{~m}$, y se eliminan los chupones que se desarrollan por encima de dicha altura. El descope no es considerado un tipo de renovación, su objetivo es dar forma a la planta.

El descope en almácigos de café a diferencia del descope en cafetales

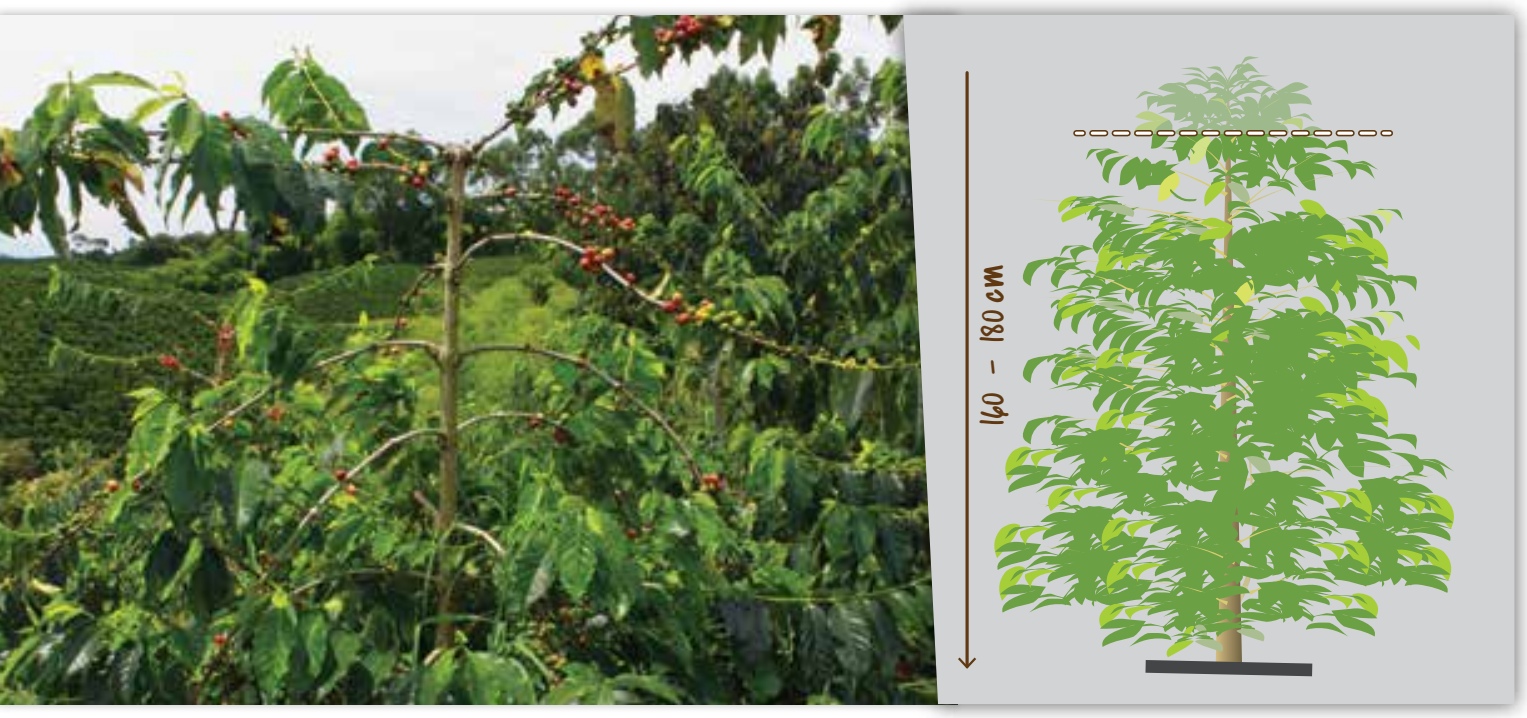


en producción, consiste en eliminar la yema terminal para promover la formación de dos tallos por planta y así aumentar la densidad de tallos en la renovación por siembra.

\section{Condiciones de uso}

- Las variedades de café de porte alto, por el tipo de crecimiento, requieren el descope para mejorar las condiciones de manejo, especialmente la cosecha. Generalmente, las plantas alcanzan la altura para descopar antes de la primera cosecha.

- Cuando las plantas son descopadas y cumplen su ciclo de producción deben renovarse por zoca común, con corte a $30 \mathrm{~cm}$ sobre el suelo. 


\section{Sistemas}

de produceión de bafí

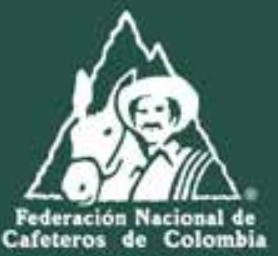

\section{Irazado en el campo}

El trazado es la disposición de las plantas en el terreno de una forma ordenada, para facilitar las labores de campo y promover espacio para los cultivos intercalados.

\section{Pendiente del terreno}

Al conocer el grado de hiclinacion de terreno se puede dalnir la distribución de las plantas y el uso de alguin modelo agroforestal.

En terrenos de alta pendiente las plantas deben distribuirse en surcos a través de la pendiente, para ayudar a la conservación del suelo y disminuir la erosión.

Distancias

Las distancias más amplias corresponden a la separación de los surcos (calles) y las cortas a la separación entre plantas.
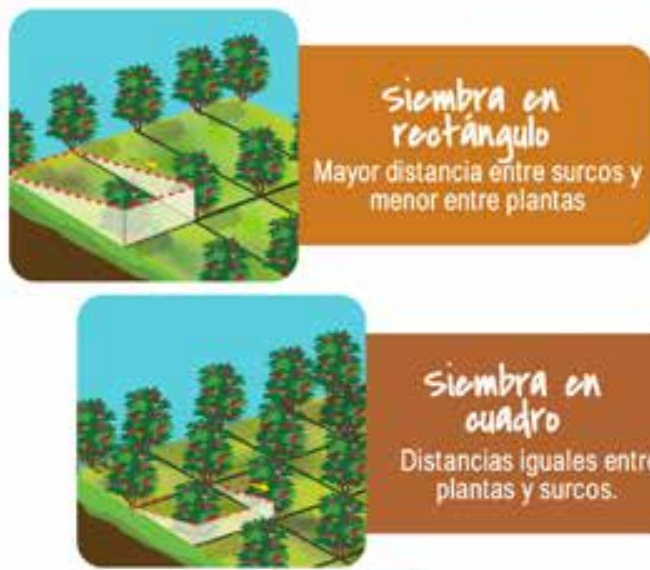

simbra on cuadro

Distancias iguales entre plantas y surcos.
Independientemente del tipo de distribución de las plantas de cafe, durante el trazado del lote planifique las áreas de separación y caminos, para facilitar el desplazamiento del personal dentro del lote

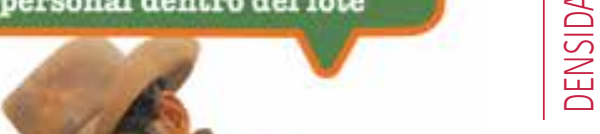

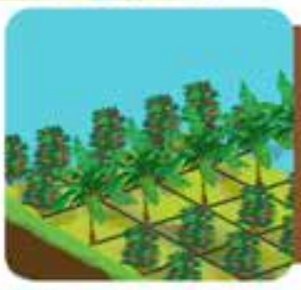

\section{Caficultor:}

La distribución de las plantas en el campo influye sobre el manejo, la duración de los ciclos de producción y la productividad del cultivo de café consulte con su Extensionista siombra en fajas oon otros cultivos

Primero se hace el trazo para el calé (cultivo principal) y se dejan blocues separados para establecer el segundo cultivo. Ejemplo: café con barreras de plátano cada $16 \mathrm{~m}$. 


\section{Sistemas de produreión de gafí}

\section{Siembra en el campo}

Para el establecimiento de los sistemas de producción de café lleve al campo colinos sanos, con un buen crecimiento y en el momento oportuno.

\section{Edad del trasplante.}

Para almácigos en bolsas de polietileno de $17 \times 23 \mathrm{~cm}$.

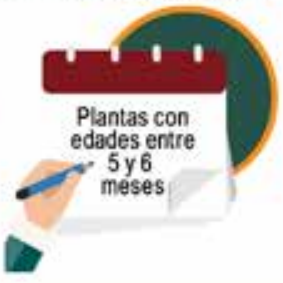

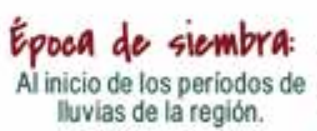

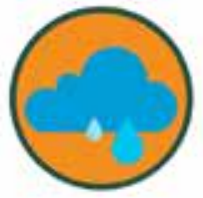

\section{Preparación del terreno:}

Antes de sembrar, planifieue las siguientes prácticas agronómicas:

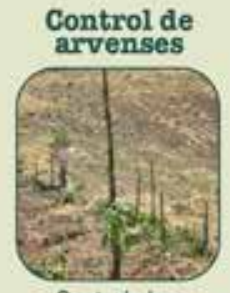

Controle las arvenses de aita interlerencia durante la preparación dellote.

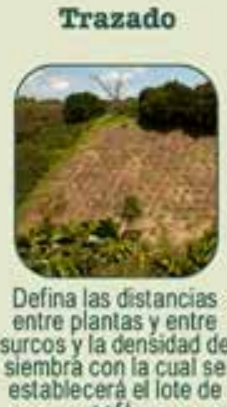
cafe.

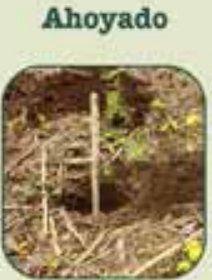

Ehoyo para la siembra debe tener un tamaño de $30 \mathrm{~cm}$ de ancho $\times 30 \mathrm{~cm}$ de profundidad.

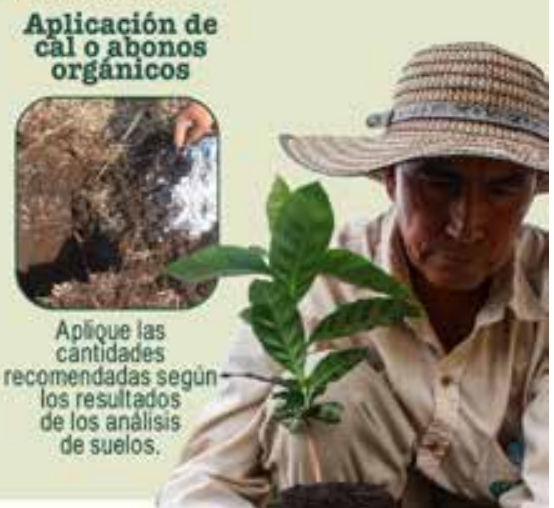

\section{siembra:}

Retire la bolsa plástica del colino de café, deposite el pilón en el centro del hoyo, adicione el suelo y apriétela desde el fondo del hoyo. El cuello de la raiz debe Quedar sobre la superficie del terreno.

\section{Caficultor:}

PlanifiQue las labores de siembra en el campo para garantizar las mejores

condiciones en las etapas de crecimiento y productividad del cultivo

\section{consulte con su Extensionista}




\section{Renovación de cafetales Por podas totales o parciales}

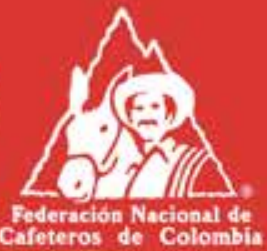

La renovación oportuna de un cultivo, ya sea mediante podas totales (200a comín) - mediante podas parciales (poda pulmón y poda callavera) debe realizarse en la epoca seca despues de finalizar la cosecha prineipal de la zona.

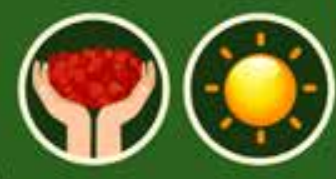

\section{Cosecha principal}

Realizar la renovación en el inicio del segundo semestre.

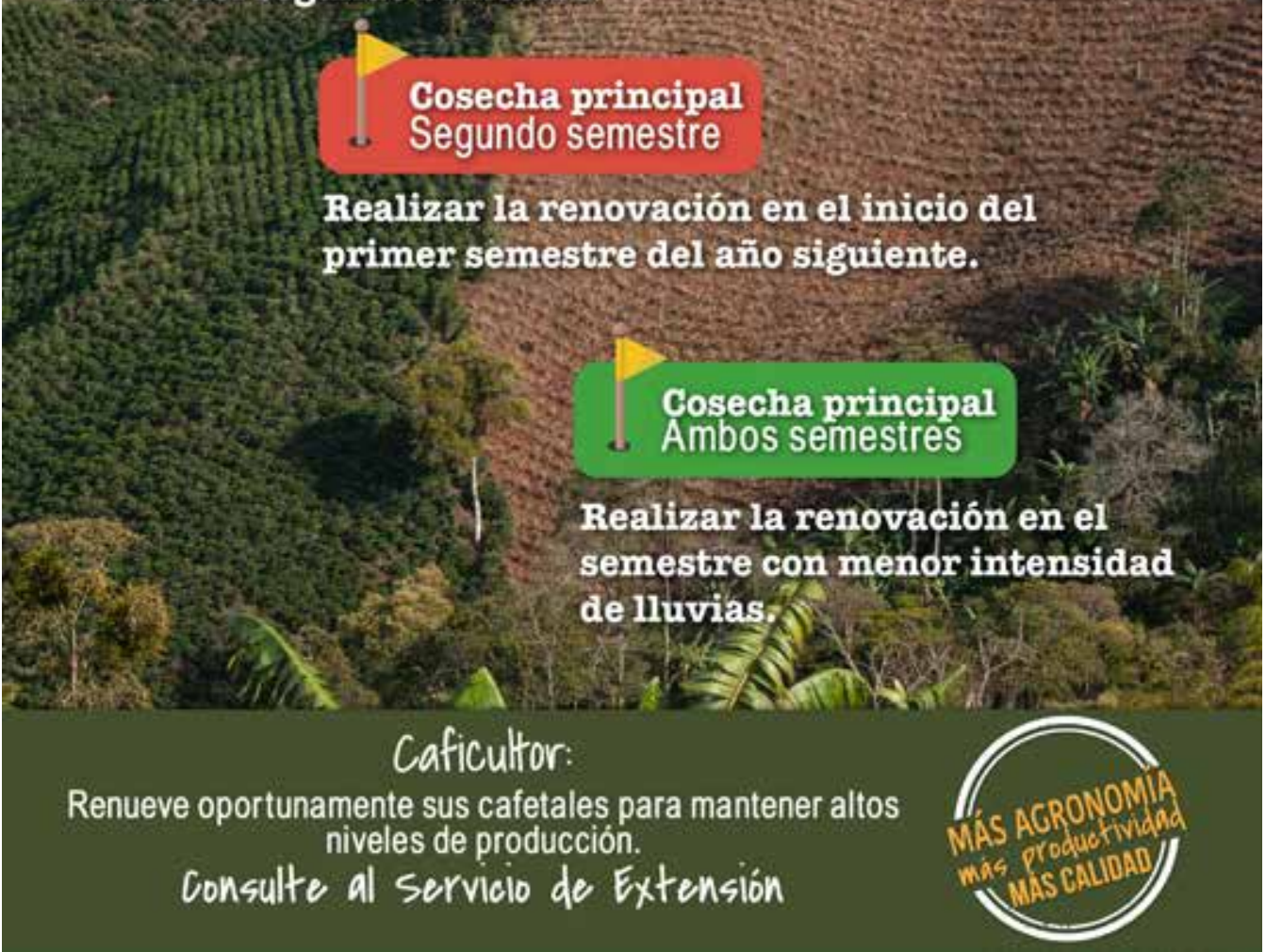




\section{Renovación nor siembra}

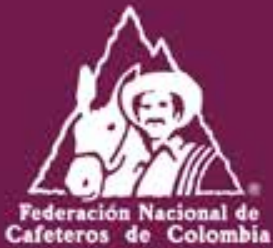

Con la siembra puede ajustarse el numero de plantas por hectárea y el arreglo espacial con el fin de alcanz ar altas producoiones y faolitar el manejo del cultivo.

\section{¿Cuándo renovar \\ un cafetal?}

La duración del ciclo de producción de un cafetal se determina cuando la producción anual comienza a disminuir notoriamente y las plantas alcanzan su máxima altura. Este momento depende a la vez de la densidad de siembra.

\section{Śpocas para renovar}

Se recomienda realizar las siembras en la época de lluvia, luego de haber finalizado la cosecha principal de la zona.

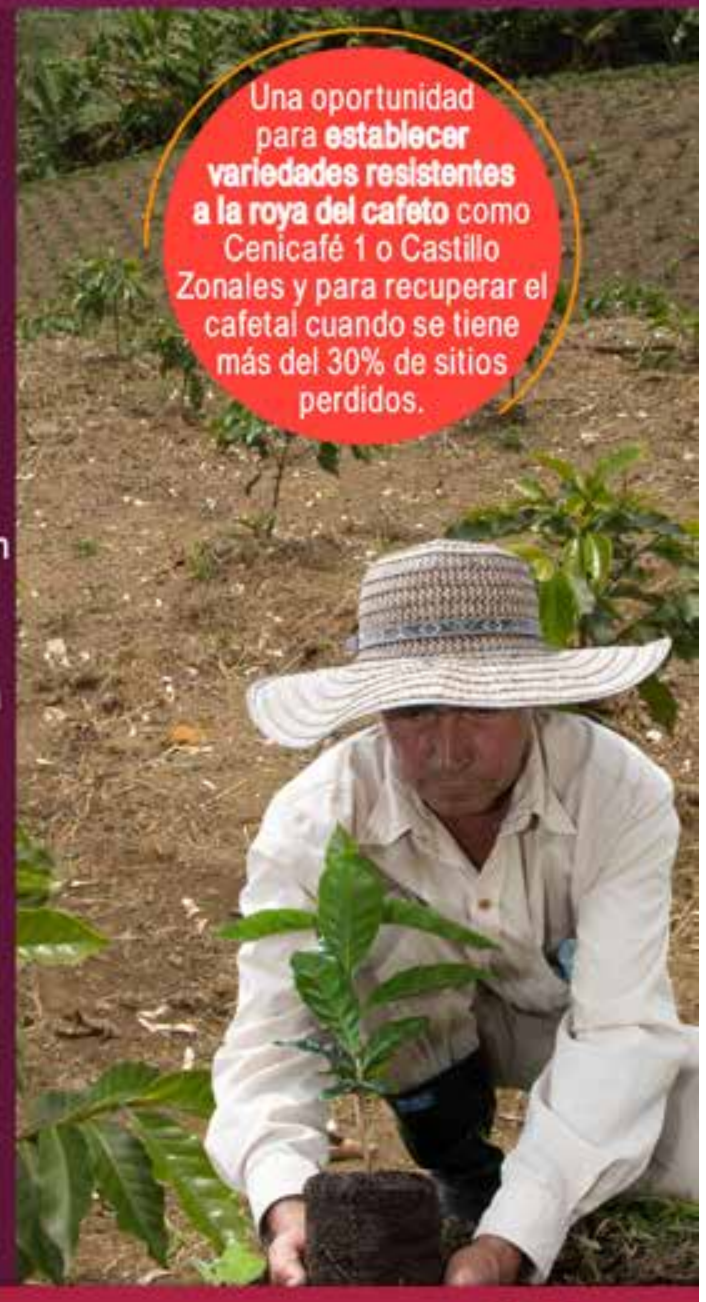

\section{Una huena siembra depende de:}

- La calidad del colino

- Una correcta preparación del terreno

- La corrección de la acidez del suelo Consulte con su Extensionista.
- Un trazo adecuado

- El tamaño óptimo de los hoyos - Una buena humedad del suelo

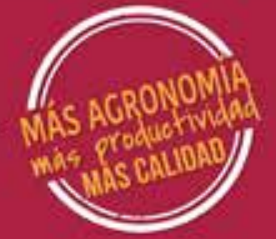




\section{Renovación de cafetales Poda Ealavera}

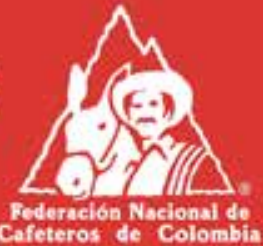

\section{Consiste en eliminar}

parcialmente las ramas de primarias del tallo ye se desarrollen a lo lakgo del mismo los brotes (chupones) o ramas secundarias.

In la poda calavera el tallo se descopa a una altura de 1,80 m y se dejan las ramas con 10 $\mathrm{cm}$ de longitud aproximadamente.

Permite estabilizar la producción cuando un alto nummero de lotes del predio han envejecido.

Debido al alto número de chupones Que se forman, la duración del ciclo productivo se reduce a dos cosechas.

Una vez el ciclo ha finalizado, las plantas deben renovarse por zoca común.

\section{Caficultor:}

La poda calavera es una alternativa temporal para ordenar la edad de los lotes de café en la finca. Consulte al servicio de Extensión

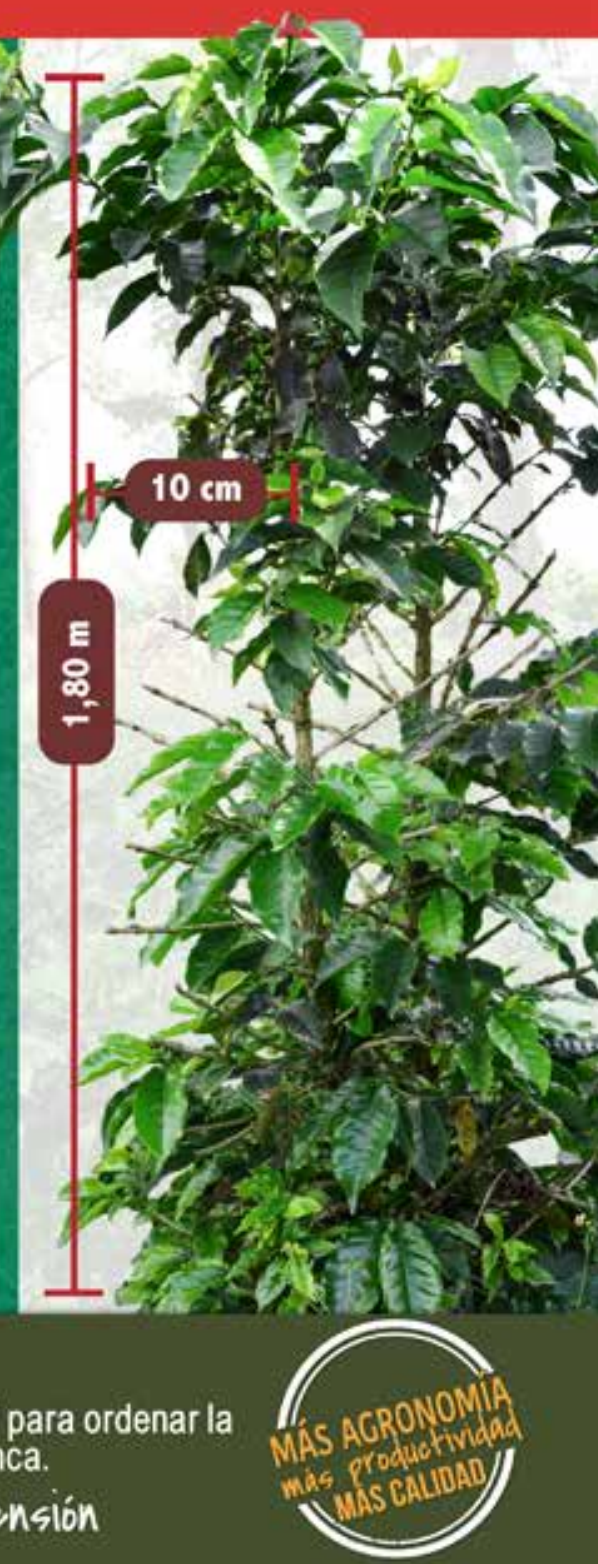




\section{Renovación de cafetales Poda Pulmón}

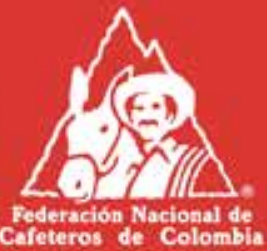

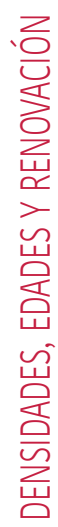

Consiste en realizar el corte del tallo principal a $60 . \mathrm{cm}$ sobre el suelo, dejando las ramas bajeras completas o podadas parcialmente, con longitudes entre los 20 y $40 \mathrm{~cm}$.

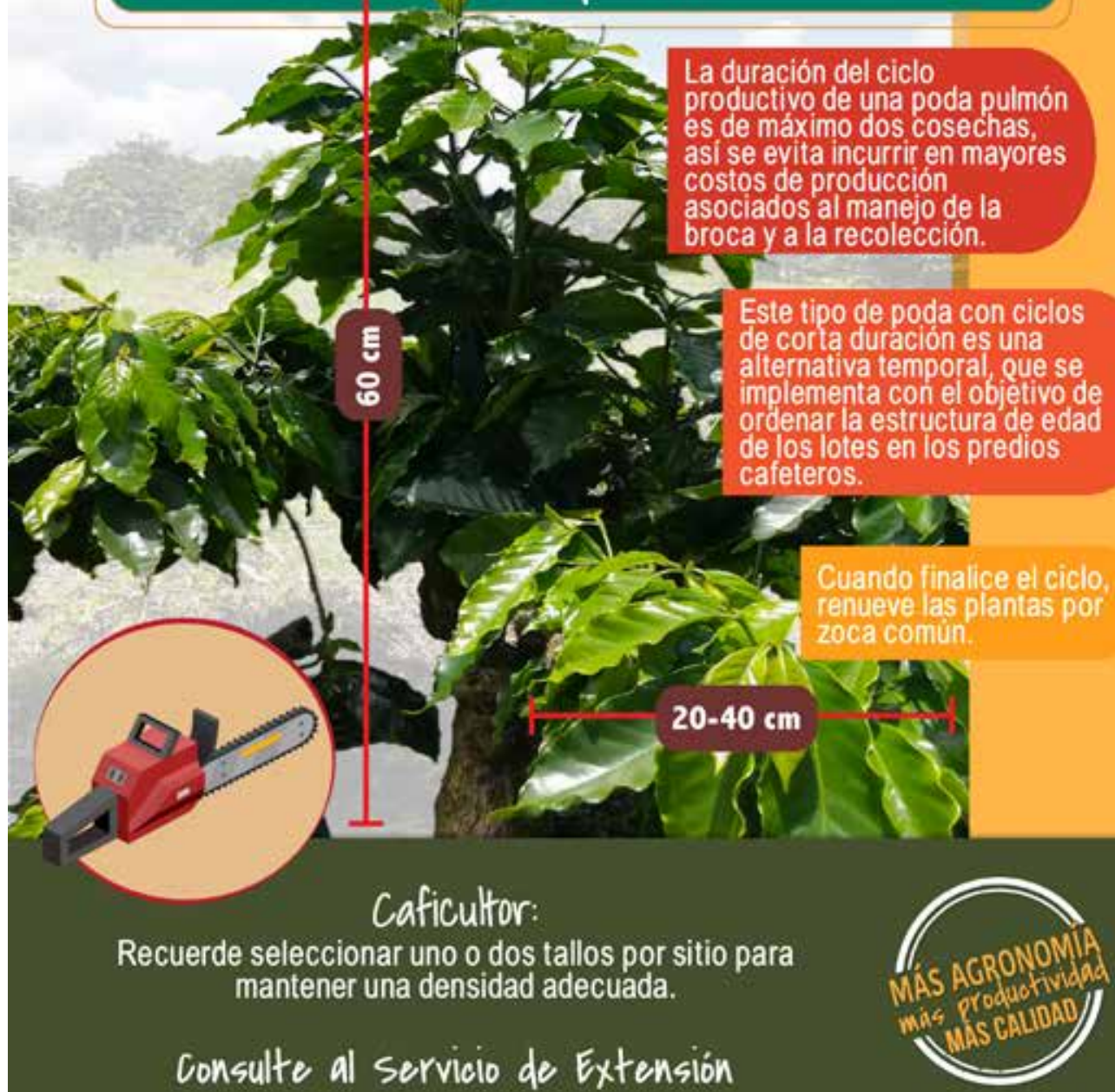




\section{Renovación de cafetales Fertilización de zocas}

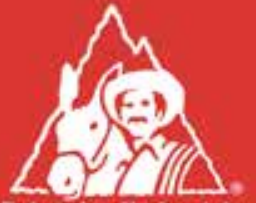

Federación Nacional de Cafeteros de Colombin

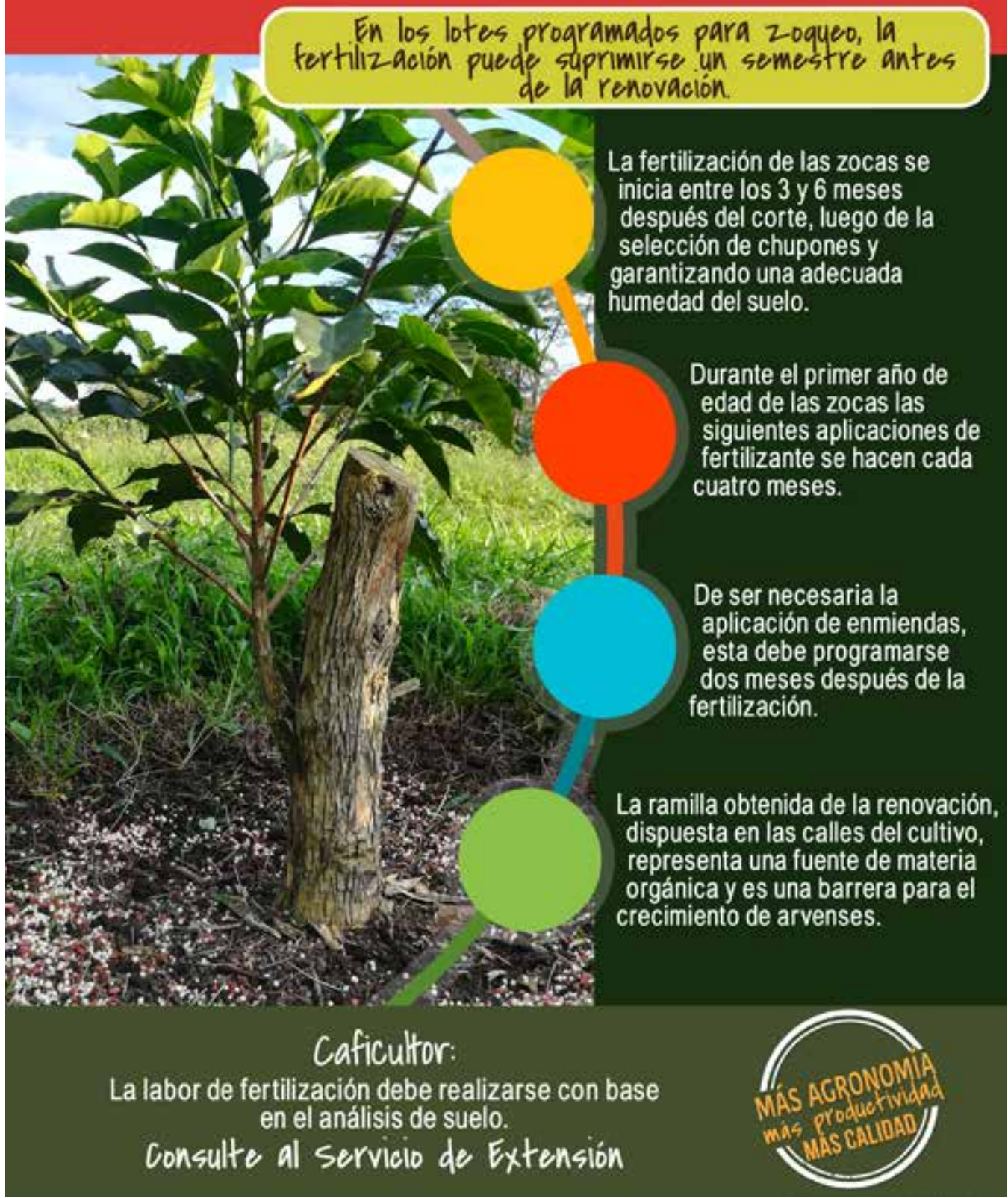

